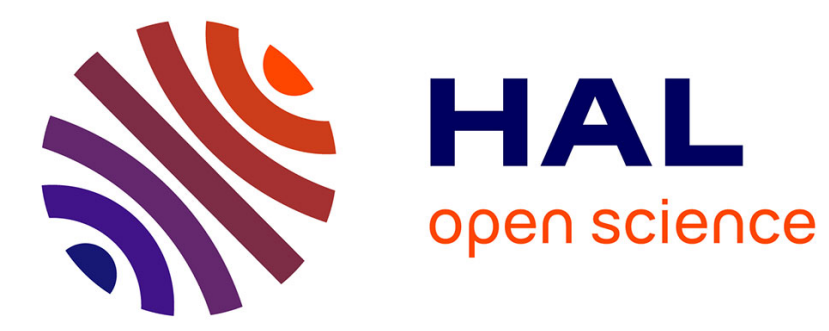

\title{
Until Death Do Us Part?: The Economics of Short-Term Marriage Contracts
}

\author{
Stefania Marcassa, Grégory Ponthière
}

\section{To cite this version:}

Stefania Marcassa, Grégory Ponthière. Until Death Do Us Part?: The Economics of Short-Term Marriage Contracts. Population Review, 2014, 53 (1), pp.19-32. hal-00935772

\section{HAL Id: hal-00935772 \\ https://hal.science/hal-00935772}

Submitted on 24 Jan 2014

HAL is a multi-disciplinary open access archive for the deposit and dissemination of scientific research documents, whether they are published or not. The documents may come from teaching and research institutions in France or abroad, or from public or private research centers.
L'archive ouverte pluridisciplinaire HAL, est destinée au dépôt et à la diffusion de documents scientifiques de niveau recherche, publiés ou non, émanant des établissements d'enseignement et de recherche français ou étrangers, des laboratoires publics ou privés. 


\title{
Until Death Do Us Part? The Economics of Short-Term Marriage Contracts
}

\author{
Authors: Stefania Marcassa and Grégory Ponthière \\ Affiliations: Université de Cergy - ThEMA (Marcassa); Ecole Normale Superieure and PSE (Ponthière) \\ Corresponding author/address: Stefania Marcassa, Université de Cergy - ThEMA, 33 boulevard du \\ Port, 95011 Cergy, France. Email : stefania.marcassa@u-cergy.fr.
}

\begin{abstract}
Under the existing marriage contracts, the default length of a marriage is the total remaining lifespan of the spouses. This paper aims at questioning the standard long-term marriage contracts, by exploring the conditions under which short-term contracts would be more desirable. Using a two-period collective household model, we show that, under general conditions on individual preferences and household production technology, short-term marriage contracts, if available, would dominate long-term contracts. Moreover, the recent equalization of bargaining power within the household is shown to make short-term contracts even more desirable than in the past.
\end{abstract}

\section{Keywords}

Marriage contracts, collective household model, length of marriage, household production technology

JEL codes: D13, D86, J12 


\section{Introduction}

In 2008, about 2,162,000 marriages were celebrated in the U.S. At the same time, the number of divorces amounted to $1,099,080 .{ }^{1}$ Moreover, as shown by Figure 1, while the marriage rate remained quite constant during the 20th century, the divorce rate was multiplied by 5 over that period.

Figure 1: U.S. Marriage and Divorce Rate per 1,000 Population

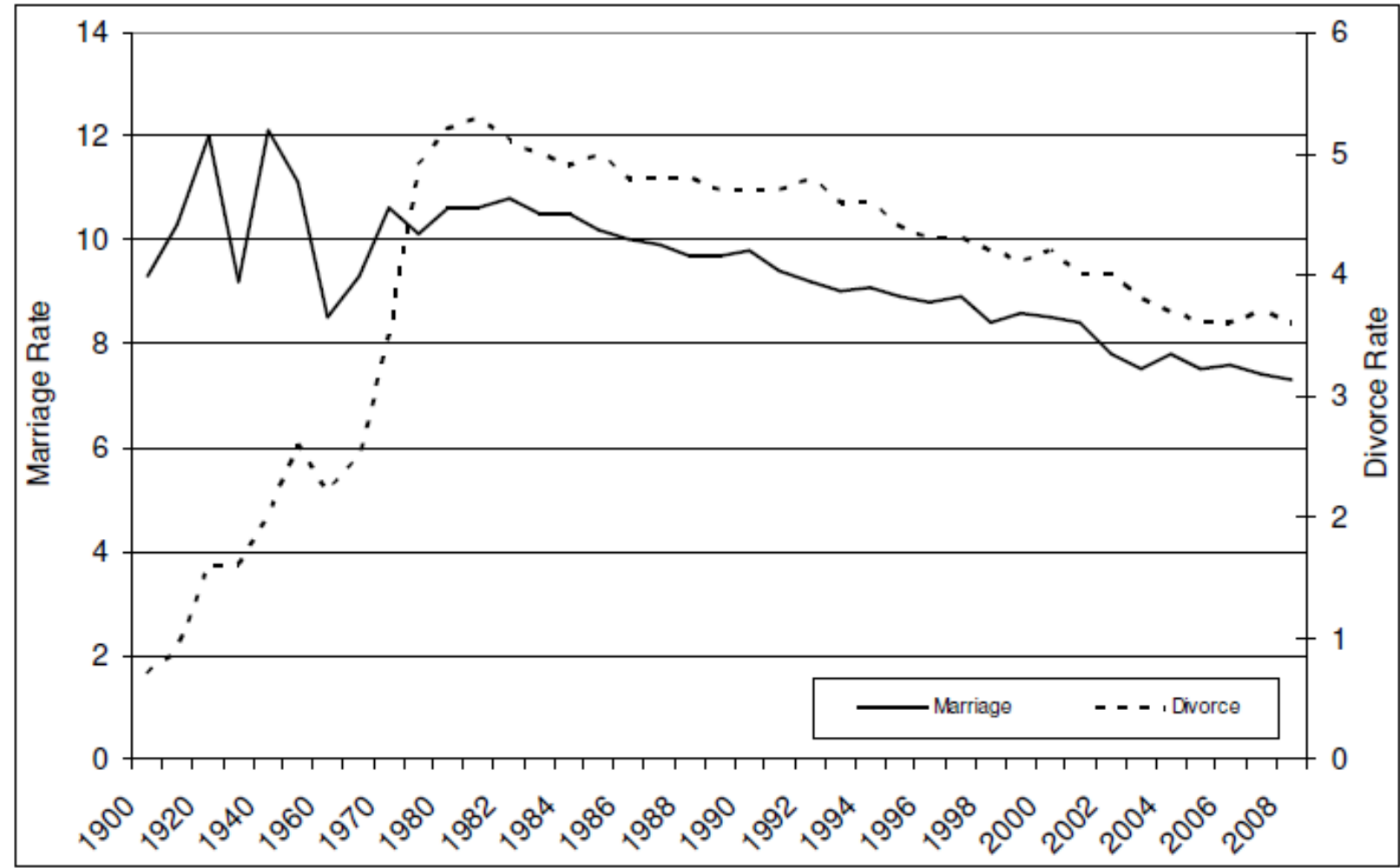

Sources: National Center for Health Statistics, U.S.

In the light of the high divorce rate, and of the non-negligible costs of divorce, we may wonder whether the traditional marriage contract is still appropriate. The existing marriage contract takes, as the default length, the total remaining lifespan of the spouses. It may make sense to propose marriage contracts with a shorter default length, that is, a short-term marriage contract, which would allow spouses to exit the marriage without costs.

This paper explores the conditions under which short-term marriage contracts, if available, would be more desirable than standard long-term contracts. Quite surprisingly, short-term marriage contracts have received little interest so far. ${ }^{2}$

In pioneer unpublished writings (1773 and 1797), Jeremy Bentham discussed the opportunity to introduce

1 The source is the National Center for Health Statistics (2010).

2 In 2009, the Australian Bureau of Statistics floated the idea of marriage licenses that expire after 5 or 10 years, unless couples renew it (see [6]). But one can find traces of such practices in the Muslim culture (the Nikah Mut'ah in the Shi'a Islam) and also in the Pre-Islamic Arab culture (the Nika'e'Misyar in Sunni Islam). 
short-term marriage contracts (see [11]). Bentham regarded these short contracts as appealing alternatives to long contracts at a time when divorce was not easily available, and as appropriate marriage contracts for the young, who would otherwise not be able to enter lifelong relationships. Bentham acknowledged that standard long-term contracts are compatible with the Principle of Utility for some couples, but wanted to add short-term contracts as these would better fit some others.

Recently, the marriage contract has attracted a large attention, but, as far as we know, little has been said on the optimal contract duration. Some issues have been addressed, such as informational constraints on outside opportunities ([10]), prenuptial contracting behavior ([7]), the actual duration of marriages ([9]) and the interval between relationships ([5]). ${ }^{3}$ Moreover, despite the considerable attention paid to the duration of agreements and contracts, the literature has not so far applied optimal duration contract analysis to the marriage contract. ${ }^{4}$

To examine the conditions under which short-term marriage contracts are optimal, various theoretical frameworks could be used, allowing for more or less complexity in terms of preferences, knowledge and household production. In this paper, we deliberately opt for the simplest framework, to provide a benchmark discussion on the duration of marriage contracts.

For that purpose, we consider a two-period collective household model where agents differ in gender and in marital status (single, married, divorced). Agents produce and consume a single good. The good can be interpreted in various ways. For instance, one can think of standard consumption goods or leisure activities. Alternatively, one can regard a child as a consumption good that is collectively produced by his parents.

Individuals make decisions on marital status at the beginning of every period. The decision on marital status depends on the costs of divorce and marriage, on the productivity gains induced by marriage, and on the bargaining power of each agent within the couple.

For the sake of simplicity, we also assume that there is perfect information and no uncertainty. Those assumptions are not neutral for the issue at stake, but will allow us to emphasize some fundamental motives supporting one marriage contract against another in that simple environment. Clearly, it is easy to think about uncertainty-based arguments for or against one type of marriage contract. ${ }^{5}$ In this paper, we abstract from those arguments, to better emphasize how the characteristics of the household production technology and of individual and couple's preferences influence the desirability of one marriage contract over the other.

We show that, under general conditions on individual preferences and household production technology, short-term marriage contracts, if available, would dominate long-term contracts. It is only in the special case of time-invariant or time-increasing household productivity, that the long-term contract dominates the short-term contract. Moreover, the recent equalization of bargaining power within the household is shown

3 Various aspects of marriage are also discussed in [4].

4 The optimal contract duration has been studied in other economic fields (see [8], [3], [2], [1]).

5 One can think, for instance, of the insurance motive for long-term marriage, which is related to the insurance provided by the spouse's income. There exists also an uncertainty argument for short-term contracts, which could be regarded as less risky in a world of imperfect information about the spouse's characteristics. 
to make short-term contracts even more desirable than in the past.

The paper is organized as follows. Section 2 presents the framework. Short-term and long-term marriage contracts are compared in Section 3. Section 4 concludes.

\section{The model}

We consider a two-period model, with two types of agents, males and females, denoted by the superscripts $m$ and $f$. We assume an equal number of men and women.

We consider two kinds of marriage contracts, which differ in their duration. On the one hand, agents may choose a long contract, which lasts for the rest of the life of the spouses (i.e. the two life-periods), except if there is a divorce. On the other hand, agents may choose a short marriage contract, which lasts for only one period, after which agents become singles again, at no cost. Hence the main difference between the two contracts concerns the exit cost and the continuation cost.

At the beginning of the first period, all agents are single (S). They receive a random marriage offer from an agent of different gender. The marriage offer only includes the consumptions in the two periods. ${ }^{6}$ Agents decide either to remain single (S), or to get married, under either the short-term (MS) or the longterm marriage contract (ML). At the beginning of the second period, agents have diverse options, depending on their marital status chosen at period 1. If they are single (S), they can choose either to remain single (S), or to get married (MS or ML). If they are married under the long-term contract (ML), they can choose to divorce (D) or to remain married (ML). If they are married under the short-term contract (MS), they can choose to become single (S) or to marry again (ML or MS). ${ }^{7}$ Figure 4 in the Appendix is a graphical representation of all possible decision nodes under the two types of marriage contract.

Agents have a period utility function that is logarithmic in consumption. Lifetime welfare takes a standard time-additive form, with a pure discount factor denoted by $\beta$. The household values the weighted sum of spouses utilities, with weights representing the bargaining power of each spouse, respectively $\mu^{m}$ for men and $\mu^{f}$ for women. We assume that $\mu^{j} \geq 0$ and $\mu^{m}+\mu^{f}=1$.

On the production side, all agents inelastically work for the entire period of time, and have an individual productivity parameter denoted by $I$. There is no differences in individual productivity of agents, and they all produce the same good. The model allows for a large set of interpretations, depending on what the unique good consists of. One can think of it as a standard consumption good (consumed individually but produced either individually or in couples), or as a leisure activity. ${ }^{8}$ Married agents cooperatively combine individual productivities to produce a total amount of good equal to $\eta 2 I$, where $\eta>0$ is the efficiency

\footnotetext{
6 Note that the present model is extremely simplified regarding the matching process. As such, this eliminates a potential determinant of the desirability of short-term contracts.

7 This includes the possibility to renew the marriage contract with the same person, or to get married with another person.

8 One can also consider the good as a child. That interpretation imposes some restrictions on the production parameters $\eta$ and $\delta$ that are discussed below.
} 
gain (if $\eta>1$ ) or loss (if $\eta<1$ ) from marriage. ${ }^{9}$ Note that the gains or losses from marriage may not be constant over time. To take this into account, we assume that the household productivity in the second period of marriage differs from the productivity in the first period of marriage by a factor $\delta$. If $\delta>1$, the household becomes more productive as the duration of the marriage increases. That productivity gain may arise thanks to some "learning-by-doing" within the couple, or thanks to a better understanding or knowledge of the spouse. Alternatively, if $\delta<1$, the household becomes less productive over time. This may be due to the accumulation of disappointments or disagreements.

On the consumption side, unmarried agents entirely consume the product of their labor. When married, it follows from the household value function that each spouse consumes a fraction $\mu^{j}$ of the household product $2 \eta I$.

When deciding to get married or divorced, each agent compares her welfare in the two states. Then, the choice of the marriage contract (i.e. short or long) is driven by the preferences of the couple-member with the lowest bargaining power, i.e. by the $\mu^{j}=\min \left\{\mu^{m}, \mu^{f}\right\} .{ }^{10}$ The decision of getting divorced depends on the legal regime of divorce. If consensual, the willing of the agent with $\mu^{j}=\max \left\{\mu^{m}, \mu^{f}\right\}$ will drive the decision. If unilateral, the willing of the agent with $\mu^{j}=\min \left\{\mu^{m}, \mu^{f}\right\}$ will drive the decision.

The cost of getting married is a fraction $\lambda$ of the household's income, with $\lambda \in(0,1)$. The cost of getting divorced (e.g. legal fees, alimony transfers etc.) is a fraction $\gamma$, with $\gamma \in(0,1)$, of the household's income.

The problem faced by a single agent at the beginning of $t=1$ depends on the kind of marriage contract available. We describe the agent's optimization problem under three cases: (1) only long-term contracts are available; (2) only short-term contracts are available; (3) both contracts are available. For each case, we also provide the solution to the optimization problem.

1. Long-term contract: Single agents who get married solve the following problem:

$$
\begin{aligned}
& S_{1}^{j}=\max _{\left\{c_{1}^{j}\right\}}\left[\log c_{1}^{j}+\beta\left\{\begin{array}{l}
M_{2}^{j} \text { if remain married } \\
D_{2}^{j} \text { if divorced }
\end{array}\right]\right. \\
& \text { subject to }: c_{1}^{j} \leq \eta(1-\lambda) 2 I
\end{aligned}
$$

The policy function $\forall j=f, m$ is given by:

$$
\left.\left.\max \left\{\log \left((1-\lambda) 2 \mu^{j} \eta \delta I\right)+\beta \log \left(\mu^{j} \eta 2 I\right)\right], \log \left((1-\lambda) \mu^{j} \eta 2 I\right)+\beta \log [(1-\gamma) I]\right]\right\}
$$

9 One can interpret the parameter $\eta$ as accounting for household economies of scale; $\eta>1$ then coincides with increasing returns in the production of the good.

10 In other words, the weakest agent in the couple has a veto right regarding both the marriage decision and the contract decision. 
2. Short-term contract: Single agents who get married solve the following problem:

$$
\begin{aligned}
& S_{1}^{j}=\max _{\left\{c_{1}^{j}\right\}}\left[\log c_{1}^{j}+\beta\left\{\begin{array}{c}
M_{2}^{j} \text { if remain married } \\
S_{2}^{j} \text { if naturally separate }
\end{array}\right]\right. \\
& \text { subject to }: c_{1}^{j} \leq \eta(1-\lambda) 2 I
\end{aligned}
$$

The policy function $\forall j=f, m$ is

$$
\max \left\{\left[\log \left(2 \mu^{j}(1-\lambda) \eta I\right)+\beta \log \left(2 \mu^{j}(1-\lambda) \eta I\right)\right]\left[\log \left(2 \mu^{j}(1-\lambda) \eta I\right)+\beta \log (I)\right]\right\}
$$

3. All contracts: Single agents who remain single solve the following problem:

$$
\begin{aligned}
& S_{1}^{j}=\max _{\left\{c_{1}^{j}\right\}}\left[\log c_{1}^{j}+\beta\left\{\begin{array}{c}
M_{2}^{j} \text { if remarry } \\
S_{2}^{j} \text { if remain (divorced) single }
\end{array}\right]\right. \\
& \text { subject to }: c_{1}^{j} \leq I
\end{aligned}
$$

The policy function $\forall j=f, m$ is

$$
\max \left\{\left[\log (I)+\beta \log \left((1-\lambda) \mu^{j} \eta 2 I\right)\right][\log (I)+\beta \log (I)]\right\}
$$

Alternatively, the agent's choices can be described by means of the decision trees in Figures 5 and 6 in the Appendix, which show the payoffs associated with the different possible paths.

\section{Short-term versus long-term contracts}

The model is solved by backward induction, starting from the decisions made at the terminal node, which corresponds to the beginning of period 2. The following Proposition summarizes the optimal choices of agent $j=f, m$ for different values of the parameters.

Proposition 1. Suppose agents are initially singles. Then:

(a) If $(1-\lambda) 2 \eta \mu^{j}>1$ and $2 \eta \delta \mu^{j}>1$ and $\delta \geq 1-\lambda$, then the long-term contract is better than the shortterm contract.

(b) If $(1-\lambda) 2 \eta \mu^{j}>1$ and $2 \eta \delta \mu^{j}>1$ and $\delta<1-\lambda$, then the short-term contract is better than the long-term contract.

(c) If $(1-\lambda) 2 \eta \mu^{j}>1$ and $2 \eta \delta \mu^{j}<1$, then the short-term contract is better than the long-term contract.

(d) If $(1-\lambda) 2 \eta \mu^{j}<1$ and $2 \eta \delta \mu^{j}>1$, then the long-term contract is better than the short-term contract.

(e) If $(1-\lambda) 2 \eta \mu^{j}<1$ and $2 \eta \delta \mu^{j}<1$, then there is indifference between the short-term contract and the long-term contract, as these are both dominated by singleness.

(f) If $(1-\lambda) 2 \eta \mu^{j}=1$ then if $2 \eta \delta \mu^{j}>1$, the long-term contract is preferred. However, if $2 \eta \delta \mu^{j}<1$, then there is indifference between the two contracts, as these are both dominated by singleness. 
Proof. To prove this Proposition it is sufficient to compare the payoffs of different path of the decision trees in Figures 5 and 6.

Take the case where household productivity is constant with marriage duration (i.e. $\delta=1$ ). Cases (b) and (c) cannot occur, so that the long-term marriage contract weakly dominates the short-term marriage contract. Indeed, if the gains from marriage are sufficiently large (i.e. a high $\eta$ ), agents prefer the longterm contract (to avoid the cost of remarriage). But if the gains from marriage are low, agents prefer being single, and are thus indifferent between the two marriage contracts.

Consider now the case where $\delta$ differs from 1. If the household becomes more productive as the marriage duration increases (i.e. $\delta>1$ ), cases (b) and (c) cannot hold, so that the long-term contract is dominant. However, if the household becomes less productive as the marriage duration increases (i.e. $\delta<1$ ), cases (b) and (c) may arise. These correspond to different motives for choosing a short-term marriage contract. In case (b), the productivity loss due to marriage duration is low, which makes the married status better than singleness in the second period. If the cost of remarriage is sufficiently low with respect to the productivity loss due to marriage duration (i.e. $\delta<1-\lambda$ ), agents prefer two short marriage contracts instead of a long one. In that case, agents want to be married, and the productivity loss induced by duration makes the short-term contract better, because it allows agents to benefit twice from the large immediate productivity gains induced by marriage (in comparison to singleness). In case (c), the productivity loss due to marriage duration, which is larger than in case (b), makes singleness more desirable than being married in the second period. That second-period singleness can be achieved at no cost under the short-term marriage contract. Hence, in this case, the short-term contract allows agents to become single for free, unlike the costly divorce under long-term contracts.

In sum, despite the absence of any risk or unanticipated event, the short-term contract may be superior, thanks to the possibilities either to marry again and benefit twice from the immediate productivity gains from marriage, or to become single for free. Note that the results of Proposition 1 are invariant to the divorce regime (unilateral or consensual). The reason is that, once short-term contracts are introduced, there are no divorces any more. Actually, a costly exit from the standard long-term marriage is strictly dominated by a free exit under a short-term marriage.

How does Proposition 1 translate into actual agreements? In particular, can this rationalize the history of actual marriage contracts? Proposition 2 provides an answer to those questions under the cases of consensual and unilateral divorces. ${ }^{11}$

Proposition 2. Table 1 and 2 summarize the contracts that are chosen by the couple when a spouse (e.g. $\underline{\mu}$ ) faces one of the cases (a) to (f) of Proposition 1, and, similarly, the other spouse (e.g. $\bar{\mu}$ ) faces one of the cases (a) to (f) of Proposition 1.

11 The cases (a)-(f) refer to the conditions on parameters stated in Proposition 1. The cell is empty when those circumstances cannot arise. 
Table 1: Marital agreements under short-term and long-term contracts

\begin{tabular}{|c|c|c|c|c|c|c|}
\hline \hline $\bar{\mu} \mid \underline{\mu}$ & (a) & (b) & (c) & (d) & (e) & (f) \\
\hline (a) & ML & & MS & ML (MS) if $\beta$ high (low) & S & S \\
\hline (b) & & MS & MS & & S & S \\
\hline (c) & & & MS & & S & S \\
\hline (d) & & & & ML (MS) if $\beta$ high (low) & S & S \\
\hline (e) & & & & & S & \\
\hline (f) & & & & ML (MS) if $\beta$ high (low) & S & \\
\hline \hline
\end{tabular}

Table 2: Marital agreements without short-term contracts

\begin{tabular}{|c|c|c|c|c|c|c|}
\hline \hline $\bar{\mu} \mid \underline{\mu}$ & (a) & (b) & (c) & (d) & (e) & (f) \\
\hline (a) & ML & & ML (S) if $\beta$ low (high) & ML (S) if $\beta$ high (low) & S & S \\
\hline (b) & & ML & ML (S) if $\beta$ low (high) & & S & S \\
\hline (c) & & & ML (S) if $\beta$ low (high) & & S & S \\
\hline (d) & & & & ML (S) if $\beta$ high (low) & S & S \\
\hline (e) & & & & & S & \\
\hline (f) & & & & ML (S) if $\beta$ high (low) & S & \\
\hline \hline
\end{tabular}

Proof. Consider case (a)-(a). In this case, both of the spouses prefer a long-term marriage contract. Consider case (a)-(c). Here, the spouse with $\underline{\mu}$ prefers a long-term contract, while the spouse with $\bar{\mu}$ prefers a short-term contract. Hence, the contract that will be chosen by the couple is a short-term contract with remarriage in the second period. The other cases are similar.

In the light of Proposition 2 (Table 1), it appears that short-term contracts, when available, dominate singleness and long-term contracts in various cases. There remain only three cases where the long-term contract prevails. First, the case where the productivity gains induced by marriage are large and persistent (i.e. case (a)-(a)). Second, the case where the distribution of power in the household is such that the man would like to have a long contract, while the woman is only interested in marriage for the second period (thanks to the returns from marriage in period 2), but is sufficiently patient (i.e. a high $\beta$ ) (i.e. case (a)(d)). Third, the case where both the man and the woman only appreciate marriage in the second period, and are sufficiently patient (i.e. cases (d)-(d) and (f)-(d)). In all other cases, what prevails is either shortterm marriage contracts (if high returns from marriage in both periods or in the first period when agents are impatient) or singleness (if low returns from marriage in all periods). Those results are invariant to the divorce regime.

Proposition 2 (Table 2) suggests that, in the absence of short-term marriage contract, all the cases where short-term contracts prevail would now involve either long-term marriage contracts or singleness, 
depending on the household production technology and the agents' preferences.

What does Proposition 2 tell us about history? To interpret the large prevalence of long-term marriage contracts, it is crucial to have a closer look at the motivations behind the emerging long-term contracts in the absence of short-term contracts. In the absence of short-term contracts, agents can be married under a long-term contract regime because of different motives: some agents are married by impatience in the sense that they are currently enjoying large household productivity gains and forget the future costs of marriage, whereas other agents are married by patience, in the sense that they are currently suffering from low returns, but hope to get more from marriage in the future. These distinct motivations have tremendous effects on what would have prevailed in the presence of short-term contracts. Actually, if agents are married by impatience in the absence of short-term contracts, those agents would have opted for a shortterm contract if this was available. On the contrary, if agents are married by patience, the introduction of short-term contracts would not necessarily affect the emerging marriage regime, as long-term contracts remain the unique way to benefit from large household returns growth over time.

Regarding the role of the distribution of bargaining power within the household, it should be noticed that a movement towards an equality of bargaining power coincides with a convergence towards the diagonal of the tables, where both agents face the same conditions. The impact of such a shift on the prevalence of short-term and long-term contracts can hardly be assessed without additional information on preferences and production parameters. Nonetheless, if we follow Bernoulli's Principle of Insufficient Reason, and consider all subcases as equally likely (and assign a probability of $1 / 2$ when there is indeterminacy within a particular subcase), we get that the short-term contract, if available, would have prevailed with a probability of 55/180. On the contrary, if we focus on the diagonal of the table only, we see that shortterm contracts would have prevailed today with a much larger probability, equal to $1 / 2$. Therefore the recent redistribution of bargaining power towards more equality makes short-term marriage contracts more desirable than before.

Proposition 2 can be interpreted in various ways, depending on what the consumption good is. If the good consists of a leisure activity consumed individually or within a couple, a major determinant of the optimal marriage contract consists of the parameter $\delta$. If the activity involves increasing returns from intracouple interactions (e.g. chess playing), $\delta$ is large, which supports long-term contracts. On the contrary, if the leisure activity involves decreasing intra-couple returns over time, then this supports short-term contracts. One can also turn back to the interpretation of the good as a child. In that context, a low $\eta$ and a high $\delta$ lead to interpret the first period of marriage as a kind of trial period, which supports a long-term marriage. On the contrary, a high $\eta$ and a low $\delta$ support a short-term contract, as the old couple can no longer bear the idea of having new children, unlike new couples.

Finally, consider some numerical illustrations showing how the prevalence of various marriage contracts depends on the parameters of the model. We assume an equal division of bargaining power, a time preference factor $\beta=0.96$, as well as a marriage cost $\lambda=0.10$. Figures 2 and 3 show the prevailing marriage agreements when the household production parameters $\eta$ and $\delta$ lie in the [0,1] interval. In the left figure, the short-term contract is available, unlike in the right figure. 
Figure 2: Numerical Exercise (1): $\lambda=0.10$

With short-term contract

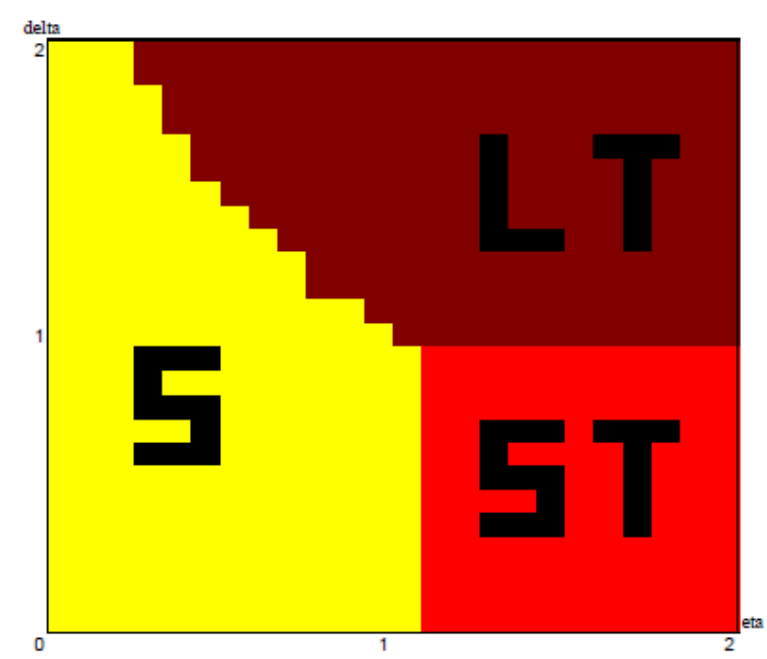

Without short-term contract

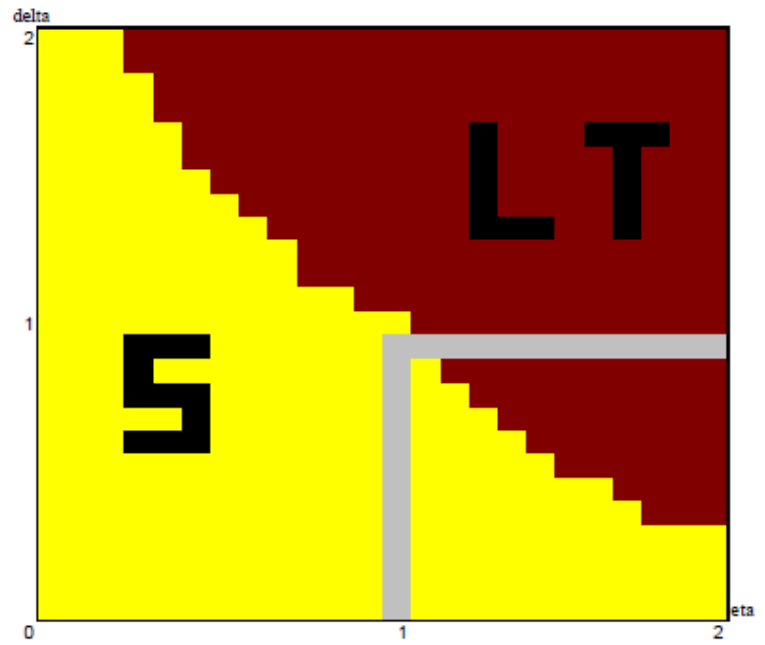

The short-term marriage contract prevails when the gains of marriage are large but temporary, that is, when the economy lies in the bottom-right corner (i.e. $\eta$ is large and $\delta$ is low). The long-term contract prevails when the gains from marriage are large and persistent, that is, when the economy is in the upperright corner. Singleness prevails in the other cases.

Figure 3: Numerical Exercise (2): $\lambda=0.05$

With short-term contract

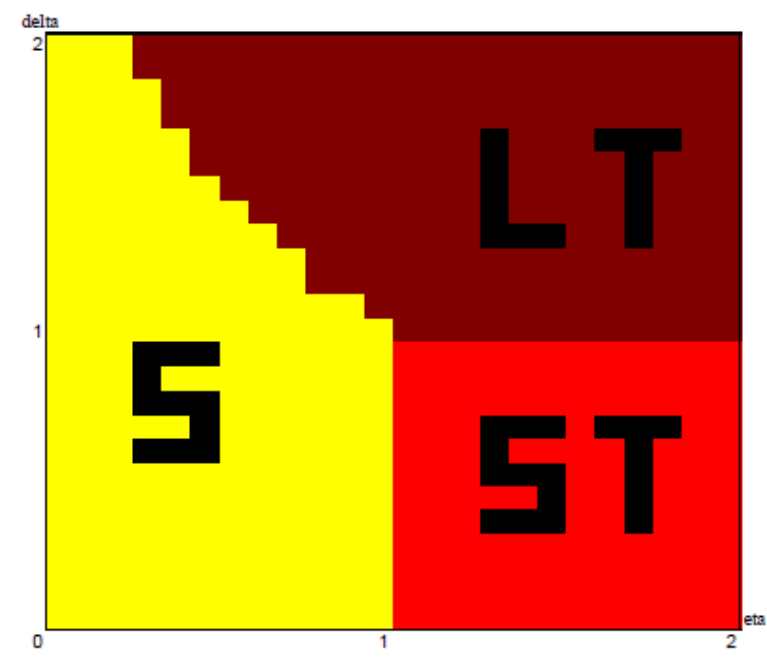

Without short-term contract

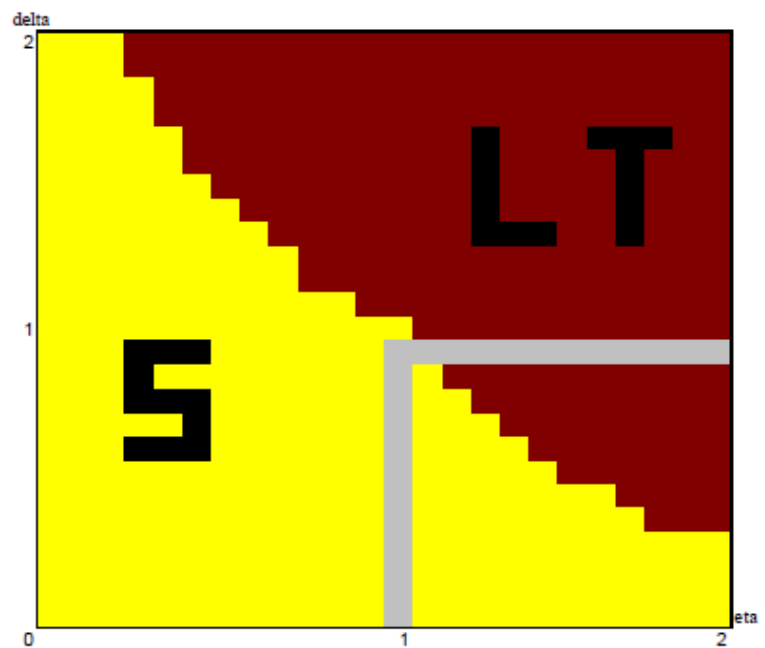

The prevalence of the short-term contract depends on the cost of marriage $\lambda$. To illustrate this claim, Figure 3 shows the case where $\lambda$ is lower than before, and equals 0.05 . Here, the short-term contract would prevail for an even larger interval of values for household production parameters. The comparison of the left and right figures illustrates that the introduction of short-term marriage contracts would not only reduce the prevalence of long-term contracts, but, also, of singleness, depending on the values of 
household production parameters $\eta$ and $\delta$.

\section{Conclusions}

Although the economics literature paid a large attention to various aspects of the marriage contract, the issue of the optimal duration of the marriage has remained largely unexplored. In this paper, we developed a simple two-period collective household model where agents make decisions about their marital status at different points in time, and choose between long-term and short-term marriage contracts.

Our conclusions are the following. First, provided the household production technology involves decreasing returns from cooperation over time, the short-term contract dominates the long-run one under a large interval of values for preference and production parameters. Second, the overall impact of introducing short-term contract depends ultimately on what currently drives the marriage decision. If agents marry by patience, then the long-term contract would still largely prevail despite the introduction of a short contract. On the contrary, if individuals currently marry by impatience, then the short-term contract would partly replace either the long-term marriage or singleness. Third, a more equal distribution of the bargaining power within the household favors also the short-term marriage contract.

Finally, it may be worth to emphasize some limitations of the present work, which invite further research. First, although one could interpret children as the produced good, it remains that the fertility decision may affect the marriage decision in a more complex way than described in our model. In particular, children could matter not only as consumption goods, but also as investment goods, or as an object of parental altruism. Second, this model includes only one type of externalities (i.e. production externality within the couple), and leaves other externalities aside (e.g. jealousy of some couples, social norms). Third, this model is purely deterministic. Obviously real-life marriage decisions involve risk, and this may affect the desirability of the two kinds of marriage contracts. Hence much work remains to be done in the future. 


\section{Appendix}

Figures

Figure 4: Decision Nodes

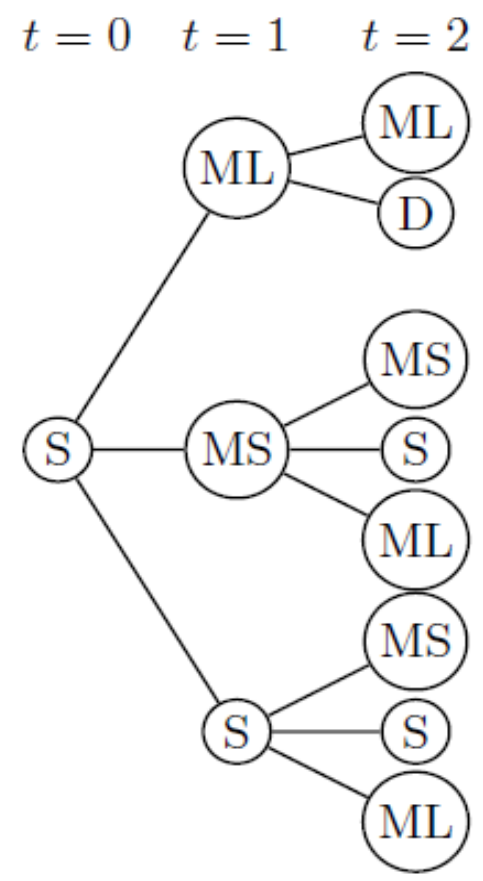

Figure 5: Decision Tree - Long-term Contract

PAYOFFS FOR AGENT $\mathrm{J}, \forall \mathrm{J}=\mathrm{F}, \mathrm{M}$

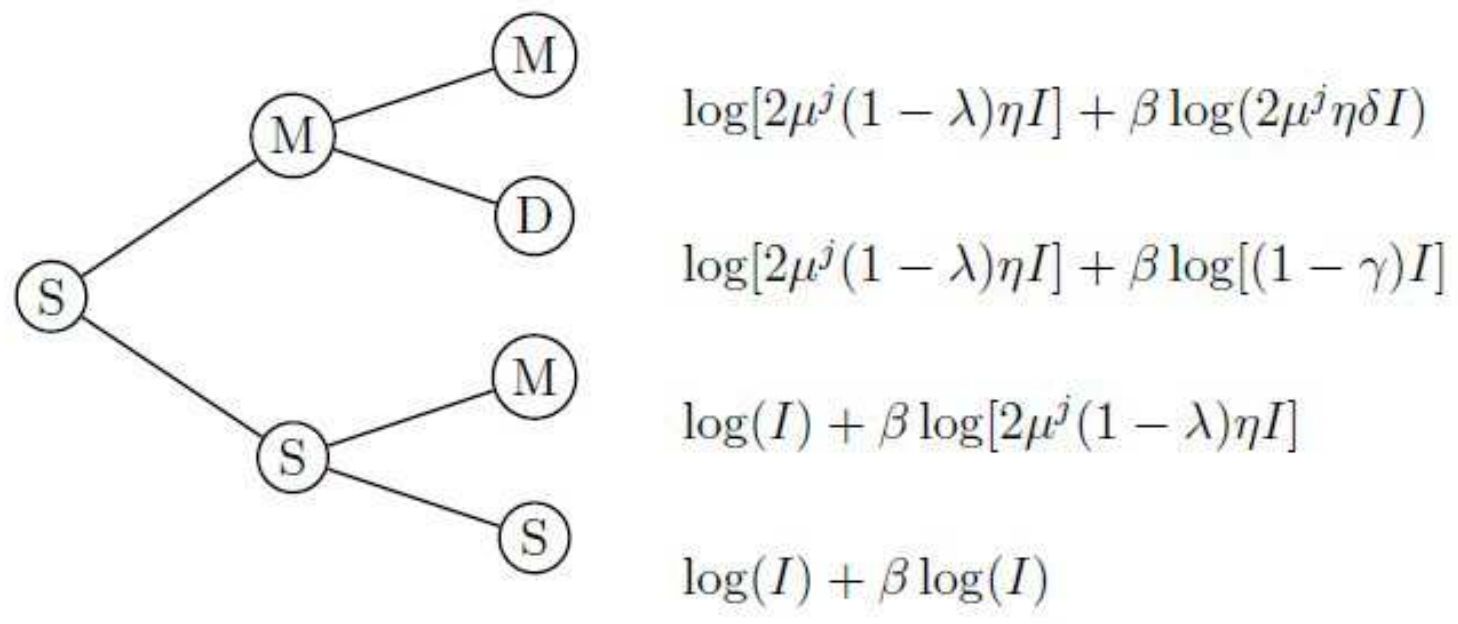


Figure 6: Decision Tree - Short-term Contract

$$
\text { PAYOFFs FOR AGENT J, } \forall \mathrm{J}=\mathrm{F}, \mathrm{M}
$$

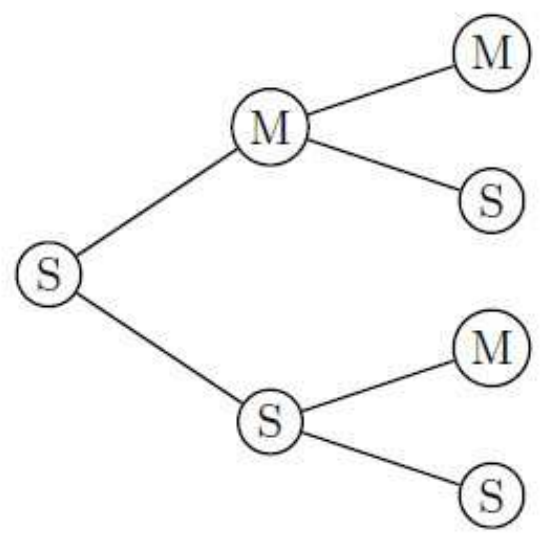

$$
\begin{aligned}
& \log \left[2 \mu^{j}(1-\lambda) \eta I\right]+\beta \log \left(2 \mu^{j}(1-\lambda) \eta I\right) \\
& \log \left[2 \mu^{j}(1-\lambda) \eta I\right]+\beta \log (I) \\
& \log (I)+\beta \log \left[2 \mu^{j}(1-\lambda) \eta I\right] \\
& \log (I)+\beta \log (I)
\end{aligned}
$$




\section{References}

[1] O. Blanchard and A. Landier. The perverse effects of partial labour market reform: fixed-term contracts in france. Economic Journal, 112(480): F214-F244, June 2002.

[2] R. M. Cantor. Work effort and contract length. Economica, 55(219):343-53, August 1988.

[3] V. P. Crawford. Long-term relationships governed by short-term contracts. American Economic Review, 78(3):485-99, June 1988.

[4] A. Dnes and R. Rowthorn. The Law and Economics of Marriage and Divorce. Cambridge University Press, 2002.

[5] J. Ermisch. Trying again: Repartnering after dissolution of a union. ISER Working Paper, 2002.

[6] H. Goltz. Fixed-term marriage contracts. Discussion Paper, April 2009.

[7] G. Hamilton. Property rights and transaction costs in marriage: Evidence from prenuptial contracts. The Journal of Economic History, 59(01): 68-103, March 1999.

[8] M. Harris and B. Holmstrom. On the duration of agreements. International Economic Review, 28(2): 389-406, June 1987.

[9] N. Matouschek and I. Rasul. The economics of the marriage contract: Theories and evidence. Journal of Law \& Economics, 51(1): 59-110, 022008.

[10] H. E. Peters. Marriage and divorce: Informational constraints and private contracting. American Economic Review, 76(3): 437-54, June 1986.

[11] M. Sokol. Jeremy Bentham on love and marriage: A utilitarian proposal for short-term marriage. The Journal of Legal History, 30(1): 1-21, 022009. 